\title{
Electricity Generation from Roads by Using Flip Plate Mechanism
}

\author{
Digvijay B. Kanase, Dhanashri Patil, Mrunali Patil, Aniket Pharne, and Prashanti Waware
}

\begin{abstract}
Food, clothes and shelter are the basic need of human beings. Now a day's electricity also the basic need of people. Electricity is one of the most important part of humankind. Our India is a developing country. So, for development of domestic and industrial purpose there is huge demand of electrical energy. The electricity is the most popular form of energy and its demand in the country has been increasing day by day. There are two type of energy generation conventional and non-conventional. Conventional energy sources are solar energy, wind energy etc. Non-conventional energy sources are hydro, nuclear etc. But all conventional and non-conventional energy sources require high installation cost. Also, all conventional sources are based on environmental conditions. Our main moto is to design a conventional source that will overcome all this drawback. In this paper we are designing such model using flip plate which generate the electricity. For generation of electricity we have to use DC generator with flywheel and produced electricity is stored in DC battery. This stored electricity is used for lightning purpose. This system is installed on the road where continuous flow of vehicles is present.
\end{abstract}

Keywords-Battery, DC generator, Flip Plate, Flywheel, etc.

\section{INTRODUCTION}

Electricity is the important part of our daily life. It is a basic need for home and industries. All the devices of home, business, schools, colleges, hospitals, market area, temples etc. are dependent on the electricity. Electricity was generated from various conventional energy sources and non-conventional energy sources. Mostly the conventional energy sources like hydro power plant and thermal power plant are the maximum sources of electricity. Similarly, electricity is obtained from other sources like solar, wind, natural gases, tidal etc. which are non-conventional. Mostly the hydro power plant is used for peak load which has required less time to start the plant. And thermal power plant is used for base load which require the more time for the start and shut down the plant. And other nonconventional sources are used for small applications in most of the time.

Day by day, requirement of electricity is increasing. Also, the use of vehicles is increasing. Some of them affect nature. There are number of vehicles passing on the road every day. The kinetic energy of vehicles wasted on road in the form of friction. We have to utilize this wasted energy. There are various methods to capture this energy. Such as piezo electric, speed breakers are installed practically. But electricity generation from flip plate is new technology and research is going on it.

So, we are designing such system which belongs to above concept and also helpful for society. So, we are designing such a system which will not pollute nature also require less floor area and will not need of fuels for its operation. This system gives pollution free electricity, no barrier to traffic, minimum maintenance cost, also less floor area is required. So, we have to design such system which belongs from above concept also helpful for society. So, we have to design such a system which cannot pollute nature also require less area and no need of fuel. This system gives pollution free electricity, no barrier to traffic, minimum maintenance cost, also less area required.

\section{LITERATURE REVIEW}

A large amount of kinetic energy is being wasted on roads on daily basis in different forms which could be use to generate power and this power can be stored in batteries. This paper shows clearly how we can generate power by using rack-pinion method where basically linear motion is converted into rotary motion and then can be used to generate electricity. Large amount of electricity can be generated using this method and this method is ecofriendly. [5]

The principle of the electric power generation using Flip plate mechanism is very simple [3]. It is based on the same principle as in the case of electricity generation in case of hydroelectric power plant, thermal electric power plant, nuclear power plant, geothermal energy, wind energy, tidal energy etc. In all of the above power plant mechanical energy is converted into electrical energy. In this setup also, mechanical energy is converted into electrical power using a D.C. generator. Here the vertical motion of the top of the Flip Plate is converted into the rotational motion, which in turn rotates the generator and generates electricity. [4]

The proposed design offers pollution free power generation, would cause no obstruction in traffic, leading to low budget electricity production. It would occupy less floor area and its maintenance would be easy. The power generated by this technique can be used in street lights, road signals, lighting of the bus stops, lighting of the check post on the highways, etc.[7] As identified by Aswathaman [7], three different mechanisms are currently being used in power generation via speed breakers. These are: Roller type mechanism $[8,9]$, the Rack- Pinion mechanism [7,10], Crank-shaft mechanism [11].

Singh et al. [12] discussed rack pinion mechanism to generate electricity. They proposed mechanism using chain sprocket and springs with rack pinion to generate electricity. Vehicle was passed over that mechanism and then due to rack pinion there was rotation in gears and shafts moved with chain sprocket movement. Dc power was generated and was stored in a battery and then using an inverter they changed that $\mathrm{dc}$ in ac power. 
Das et al. [13] proposed mechanism in which electricity was produced by kinetic energy of speed breaker. The basic principle was when a car passes over the jump or dome which is the device use in place of jump the dome will go down due to weight of car while moving car possess kinetic energy that kinetic energy will be converted into rotational energy with the help of rack and pinion. A fly wheel was mounted on the shaft whose function was to make energy uniform. That shaft is connected through a belt with dynamos. These dynamos were used to convert mechanical energy in electrical energy. The power was generated in both directions. They used Zenor diode to generate power in opposite direction too.

\section{PROBLEM STATEMENT}

In our country the electricity generated from the renewable sources. For example, solar energy, wind energy etc. but not every form of renewable energy is commercially viable. Also, they are less efficient, depends on environmental conditions. Also, they all are location specific and requires storage capabilities. They require large space for installation. Now a day's demands of electricity in countries are increasing. All devices are working on the electricity. Also, the use of vehicles increasing day by day. There is continuous flow of vehicles on the roads. So, more tons of energy wasted in the form friction. By capturing this energy, we have to convert it into useful electrical energy. We have to design such system which requires less space and low installation cost. Generation of electricity is not affected by any environmental conditions.

\section{METHODOLOGY}

1. Flip plate: In this project the two flip plates are mounted on the road surface. As wheel of the vehicle reaches upper most position of the plate, plates get slide toward guide.

2. Connecting rod: Frame is installed under the road. It can give the support to plates

3. DC generator: The d. c. Generator converts the rotation of smaller pulley into electricity

4. Voltage booster: We have to give fixed voltage as per the rating of battery. So adjustable voltage booster is used for boosting the voltage or step down the voltage.

5. Battery: The output produced by dc generator is used to charge the battery and is used for various purposes.

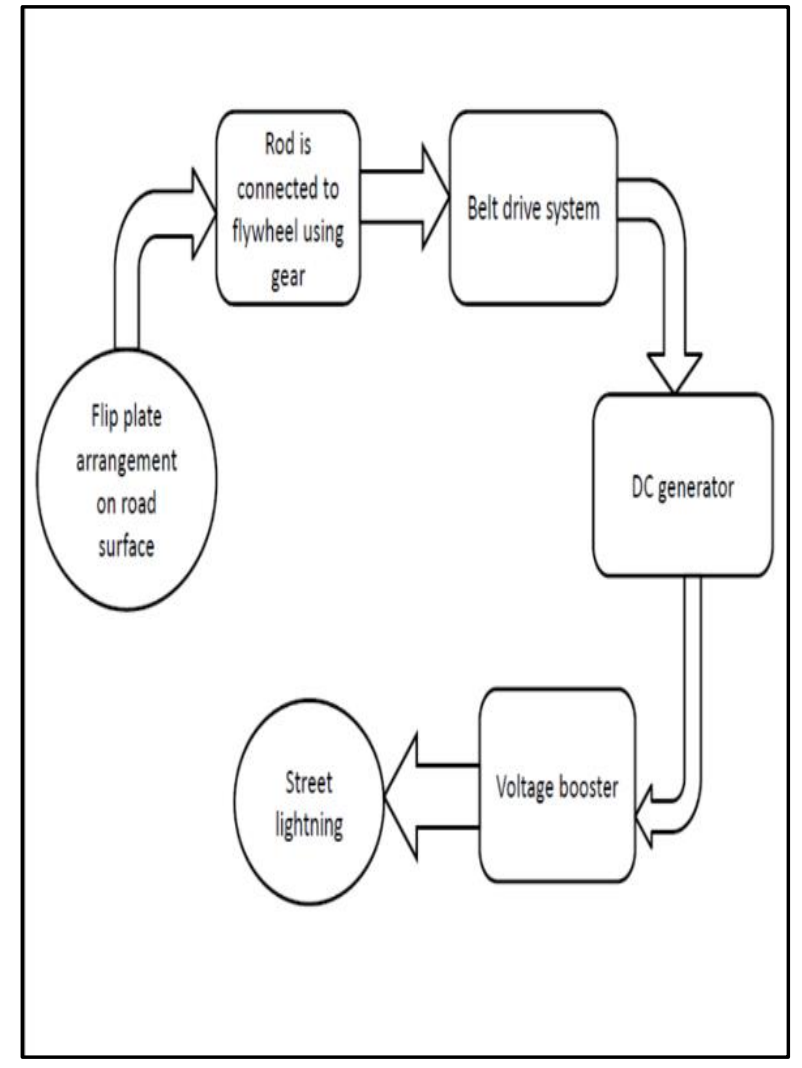

Fig.1. Block diagram

\section{WORKING PRINCIPLE}

The principle of the electric power generation using flip plate mechanism is very simple. It is based on the same principle of electricity generation from hydroelectric power plant, thermal power plant, solar power plant, wind energy etc. In these power plant mechanical energy is converted into electrical energy, using dc generator.

Electricity generation using flip plate mechanism is a system design to capture wasted kinetic energy from all vehicles. This flip plate mechanism converts the kinetic energy of vehicle into electric energy. This is done by flip plate installed on road surface. Plates are installed in bituminous layer.

Remaining setup is installed below the bituminous layer of road. The material of the plates is cast iron. Middle plate is moving plate and other two are fixed plates. When wheel of vehicle passes over the uppermost portion of flip plate, plate moves forward and backward direction. This linear motion of plate capture by the rod which is connected between flip plate and flywheel. The material of rod also cast iron.

The diameter is $30 \mathrm{~cm}$. This linear motion gives to flywheel and flywheel gets rotated. This rotational motion gives to dc generator which is coupled to flywheel with the help of belt 


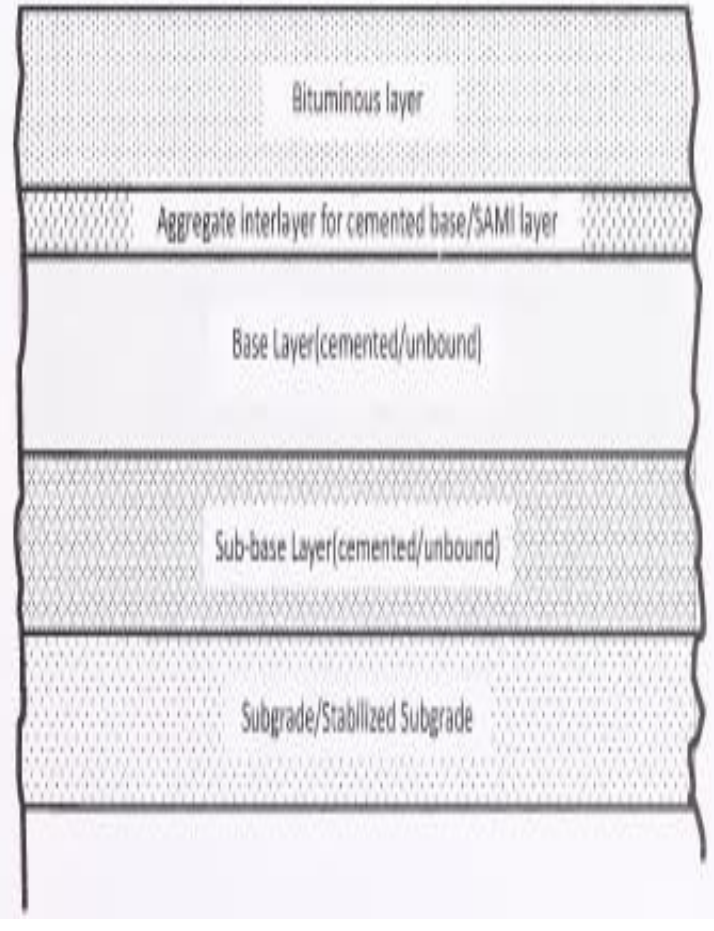

Fig.2. Different Layers of Bituminous Pavement

As per the principle of generator it converts rotational motion into electric energy i.e. Conversion of mechanical energy into electrical energy. We need to store the electric energy into battery. For rated voltage we have to use voltage booster. The voltage booster is automatic controlled. When the voltage gets high then it boosts down using voltage booster, and when voltage gets decrease then it boosts up using voltage booster and stored the electric energy into battery, these stored energies we use for street lightning, charging stations, malls, etc.

\section{Flow Chart:}

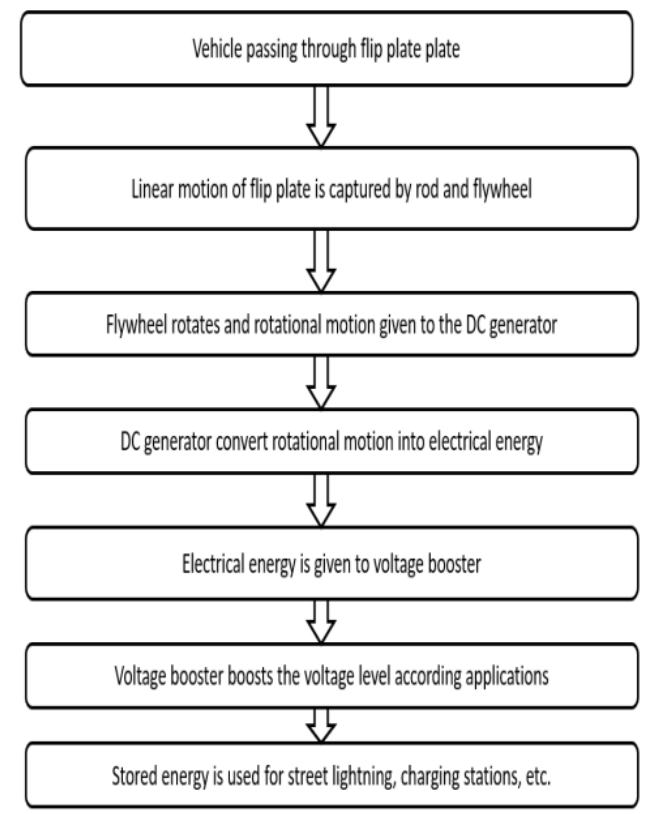

\section{MATHEMATICAL CALCULATIONS}

\section{A) Case study}

Assume the weight of the vehicle (two-wheeler) $=300 \mathrm{~kg}$ Average speed of the vehicle $=25 \mathrm{~km} / \mathrm{hr}$.

Maximum height of the plate $=10 \mathrm{~cm}$

By using the above consideration mass of vehicle over the flip plate $=300 \mathrm{~kg}$

Height from the road surface $=10 \mathrm{~cm}$

Work done $=$ force $*$ distance

But, distance $=10 \mathrm{~cm}=0.1 \mathrm{~m}$

Force $=$ mass $*$ acceleration due to gravity

$$
\begin{aligned}
& =300 * 10 \\
& =3000 \mathrm{~N}
\end{aligned}
$$

Therefore,

Work done $=3000 * 0.1=300$ watt

So that it is a power developed for 1 vehicle passes through flip plate in 1 min. $=5$ watt

Power developed for $1 \mathrm{hr}$. $(60 \mathrm{~min})=300$ watt

If the flip plate getting the continuous flow of vehicle supply then the power developed in $24 \mathrm{hrs}$. is, $300 * 24=7.2 \mathrm{kw} /$ day

This output is getting when the continuously flip plate is on the working condition. Their motion is continuous if the continuous supply is getting to it.

B) Output from hardware:

\begin{tabular}{|l|l|l|l|}
\hline \multicolumn{3}{|c|}{ OUTPUT } \\
\hline Strokes & Revolutions & Voltage & Current \\
\hline Slow & 1 & & \\
\hline Medium & 2 & $3 \mathrm{v}$ & $0.5 \mathrm{~mA}$ \\
& & & \\
\hline Fast & - & $21 \mathrm{v}$ & $1 \mathrm{~mA}$ \\
\hline & & & $0.8 \mathrm{~mA}$ \\
\hline & & & \\
\hline & & & \\
\hline
\end{tabular}



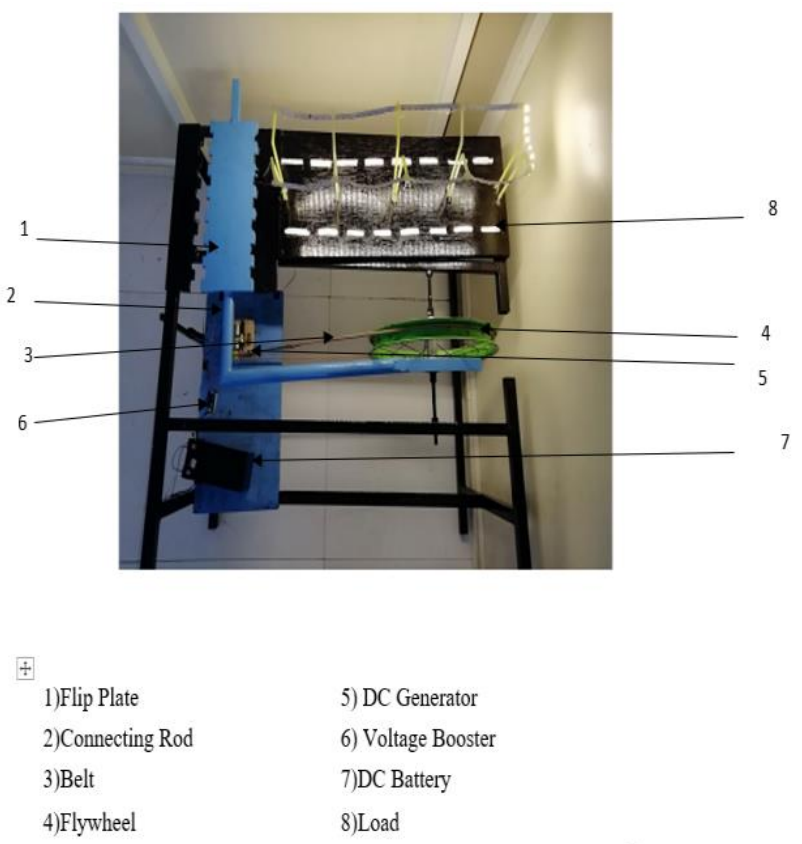

Fig.4. Hardware Implementation

\section{ADVANTAGES}

- Pollution free power generation.

- Low installation and maintenance cost.

- No manual work is required during the process.

- No fuel transportation.

- Less floor area.

- No obstructions to traffic.

- Suitable at parking of multiplexers, malls, tolls, signals, etc

- Energy available all the year.

\section{APPLICATION}

- Electricity generation using flip plate mechanism can used in most of the places such as,

- Local power generation

- Street lightning.

- Charging stations for electrical vehicles.

- On the all Highways.

- Sign boards on the roads.

- Exit of schools, colleges and companies.

\section{CONCLUSION}

Through this mechanism we can use wasted kinetic energy from vehicles and converting it in electrical energy. Wasted energy is in the form of friction. This is done by moving plate installed on the road, this plate captured very small movement from the road surfaces and it transferred to flywheel system. The captured energy is converted into electricity which is fed into power grid. From this mechanism can minimize the energy crisis. The electrical energy is generated with low installation cost, no manual work, less floor area, no fuel transportation and no obstruction to traffic.

\section{REFERENCES}

[1] Anurag Pandey et.al "Power generation and Automation System Designing for Highway" IEEE Xplore 978-1-47996085.

[2] Ashwin Chandwani et.al "Design of Road Power Generator (RPG): an Alternate Energy Source for sustainability" IJET 10.21817 Vol9 No2

[3] C. Gowri et.al "Road Power Generation (RPG) By Flip Plate Mechanism" ISBN:978-93-86171-90-0

[4] Pranay Vijay Ashtankar et.al "Road Power Generation (RPG) by Flip Plate Mechanism" IJSETR ISSN:2278-7798

[5] Jyoti Maurya et.al "Generation of Electricity through Speed Breaker Mechanism” IJES ISSN (e): 2319 - 1813

[6] F. Noor, M. Jiyaul, Production of Electricity by the Method of Road Power Generation. Int. J. of Advances in Electrical and Electronics Engineering, Volume 1, 2011.

[7] K. Gogoi, Generation of electricity from speed breaker using crank shaft mechanism, thesis submission www.scribd.com, 2010.

[8] Singh Alok Kumar, et al. Generation of Electricity through Speed Breaker Mechanism. International Journal of Innovations in Engineering and Technology IJIET. 2013; 2(2): 20-24.

[9] Das CK, Syed Monowar Hossain, MS Hossan. Introducing speed breaker as a power generation unit forminor needs. Informatics, Electronics \& Vision (ICIEV), 2013 International Conference on IEEE. 2013.

[10] F. Noor, M. Jiyaul, Production of Electricity by the Method of Road Power Generation. Int. J. of Advances in Electrical and Electronics Engineering, Volume 1, 2011.

[11] K. Gogoi, Generation of electricity from speed breaker using crank shaft mechanism, thesis submission www.scribd.com, 2010.

[12] Singh Alok Kumar, et al. Generation of Electricity through Speed Breaker Mechanism. International Journal of Innovations in Engineering and Technology IJIET. 2013; 2(2): 20-24.

[13] Das CK, Syed Monowar Hossain, MS Hossan. Introducing speed breaker as a power generation unit forminor needs. Informatics, Electronics \& Vision (ICIEV), 2013 International Conference on IEEE. 2013. 